\title{
On the Morphological Investigation of Pt Dispersion and Structure of Alumina-Platinum Composites Obtained By Thermal Oxidation of Al-Pt Nano Thin Layers
}

\author{
Kazimierz Reszka $^{a *}$, Jerzy Morgiel ${ }^{b}$, Tomasz Rydzkowski ${ }^{c *}$ and Vijay Kumar Thakur ${ }^{\mathrm{d} *}$
}

${ }^{a}$ Division of Materials Science and Technical Ceramics, Koszalin University of Technology, Śniadeckich str.2, Koszalin 75-620,E: kazimierz.reszka@tu.koszalin.pl, Poland

${ }^{b}$ Institute of Metallurgy and Materials Science, Polish Academy of Science, Reymonta str. 25, Kraków 70-059, Poland

${ }^{c}$ Faculty of Mechanical Engineering, Koszalin University of Technology, Raclawicka 15-17, Koszalin 75-620 Poland

${ }^{d}$ Enhanced Composites and Structures Center, School of Aerospace, Transport and Manufacturing, Cranfield University, Bedfordshire MK43 0AL, UK

\begin{abstract}
This article presents the methodology for the $\mathrm{Pt} / \mathrm{Al}$ and $\mathrm{Pt} / \mathrm{Al}$ nanolaminates production as well as $\mathrm{Pt}+\mathrm{Al}$ composites using two magnetrons by preparing the oxide-metal composites through high temperature oxidation of nanofilms deposited by PVD method on a metal substrate. In this article, we described the nanostructures obtained as a result of PVD technology. The applied layers were oxidized at a temperature of $860^{\circ} \mathrm{C}$ under $\mathrm{Ar}+\mathrm{O}_{2}$ for 48 hours. SEM surface analysis of the obtained nanolaminates showed that the base of the oxidized laminates was covered with a fine wafer and whisker structure with an anisotropic growth orientation. Oxidation of composite layers provided the growth of chaotically oriented and mutually penetrable whiskers and small crystals. Analysis of nanolayers by the TEM technique indicated that the growth of oxide crystals leads to the dissipation of Pt particles. The comparison of oxide layers obtained with the Pt/Al system with oxide layers obtained with $\mathrm{Pt}+\mathrm{Al}$ composite nanofilms indicates that those obtained through the oxidation of nanofilms shows a greater surface development. This is due to the partial covering of $\mathrm{Pt}$ particles through the Al layer, which causes a very strong fragmentation of the Pt nanofilms occurring during oxidation. During the oxidation in the entire volume of nanofilms, strong stresses are created that cause numerous nano-cracks, which promotes the expansion of the surface and its high activity.
\end{abstract}

Keywords: PVD, Pt-Alumina composites, oxidation, nanofilms, SEM, TEM 


\section{Introduction}

Ceramics[1,2] and other nanomaterials[3-5] are used in a number of applications ranging from coatings[6], biomedical[7], energy[8,9], water purification[10] to sensor to name a few[4,11-16]. Metal monoliths in commonly used catalyst technologies are preoxidized to produce a fine amorphous coating. Its main task is to improve the adhesion of the deposited ceramic coating with high surface area. Ceramic compounds forming coatings are deposited using waschcoat methods and are enriched with catalytic elements[17], most commonly Rh, Pd, Pt. Systems created in this way are sensitive to high temperatures and vibrations. These are the factors that lead to the exfoliation of layers, especially in the case of the use of car catalysts. The production technology in the catalyst systems based on ceramic monoliths most commonly uses the washcoat methods that allow deposition of catalytically active elements such as $\mathrm{Pt}$ or $\mathrm{Rh}$ from solutions of chemical compounds[18][19]. The biggest advantage of these methods is relatively simple technology, while disadvantages include the irregular deposition of ingredients, their local surplus and heterogeneous dispersion. Although the technology is commercially applicable, still the products used in it are rated as shock sensitive and undergo delamination under the influence of thermal shocks. It also does not use full amount of catalytically active phase dispersed within the composite layer and on the contact surface with exhaust gases based on the weight of the composite material deposited as a layer[20,21]. A different design of catalyst systems is based on metal monoliths. Most often they are made of stainless FeCrAl containing by weight 20\% chromium, 5\% aluminum, and the addition of rare earth elements $(\mathrm{Cr}, \mathrm{Zr}, \mathrm{La}, \mathrm{Y}) \leq 0.1 \%$, where the fraction of $\mathrm{Cr}$ can vary from $18.8 \%$ to $25 \%$, and the fraction of $\mathrm{Al}$ varies from $4.7 \%$ to $7.1 \%$. Metal monoliths in the currently used technologies are subjected to initial oxidation to form a thin amorphous scale coating, whose main task is to improve the adhesion of the deposited ceramic coating with high surface development. Such coatings are deposited by washcoat methods and simultaneously enriched with catalytic elements. As with the ceramic substrate, the adhesion of these coatings is unsatisfactory due to their exfoliation and peeling while vibration during operation[22,23].

This situation requires a new look at the possibility of producing the composite ceramic-metal layers of well-integrated with the steel substrate wherein the catalytically active metal phase is active and simultaneously dispersed[24]. Due to the limited content of aluminum in the melt, resulting in appropriate mechanical, electrical and thermal (heat resistant) properties, there is limited scope for obtaining the oxide layer of suitable structural 
configuration and a developed surface. These expectations have been fulfilled by alternative technology that consists in generating the oxide layer, mainly $\mathrm{Al}_{2} \mathrm{O}_{3}$, in the process of hightemperature oxidation of steel $\mathrm{FeCrAl}$ in a controlled atmosphere in the presence of oxygen. There is also a further possibility to obtain a highly developed hybrid matrix oxide phase dispersed in the form of platinum. This requires a prior deposition of additional nanolayer systems of aluminum and platinum on the steel.

Keeping in mind the different issues, this work is focused on obtaining a new quality oxide catalyst system containing nanoparticles of metallic platinum dispersed between $\mathrm{Al}_{2} \mathrm{O}_{3}$ nanocrystallites. For this purpose, one of the PVD methods was used for depositing ultra-thin $\mathrm{Al}$ and Pt layers on heat-resistant steel foil of FeCrAl alloy. The research is focused on developing the structure and structural configuration of oxide crystals formed during the oxidation process of high-temperature foil-nanoway systems, assessing the cohesion of these crystals and dispersion of $\mathrm{Pt}$ nanoparticles due to mechanical fragmentation of the $\mathrm{Pt}$ nanoparticles by increasing oxide crystals in the Pt / Al laminate system. The focus was also on the interaction of $\mathrm{Pt}$ and $\mathrm{Al}$ in the $\mathrm{Pt}+\mathrm{Al}$ composite system for the oxide layer structure and its adhesion and Pt distribution in the layer. In the case of applications for car catalysts in which steel substrates are used, the stability of the carriers of catalytically active elements to which, inter alia, Pt and which is applicable, is a key factor of economic and environmental importance. The second important factor is the availability of substrates for catalytically active elements and the release of catalysis products from the volume of carriers. This is mainly determined by the mechanical strength of the carriers and surface development and open porosity.

So the aim of this research was to develop the nanolayer composite systems in which platinum deposited in vacuum is a dispersed phase while the role of the matrix is fulfilled by aluminum oxide that is generated by high-temperature oxidation of the substrate of stainless FeCrAl and formed by oxidation of metal aluminum (also deposited in vacuum). The composition of the steel was [wt\%] Fe -73.1, Cr -21.0 Cr, Al -5.4, Si-0.2 and other $<0,05$.

\section{Experimental}

\subsection{Deposition of Al-Pt composite layers}

Among the many known methods for the preparation of thin layers, one of the most commonly used methods i.e. PVD[25-28] was selected in this work which consists of 
spraying the monolithic $\mathrm{Al}$ and Pt material by means of DC magnetron sources. The vacuum system comprises of an oil rotary pump and a diffusion pump capable of providing a final pressure $\mathrm{p}_{\mathrm{k}}=2 \times 10^{-5} \mathrm{mbar}$ and work in the operating pressure range of dynamic vacuum with argon $\mathrm{p}_{\mathrm{r}(\mathrm{Ar})}=3.0-3.5 \times 10^{-2}$ mbar. The working chamber was equipped with a rotary handle for substrates in the form of a twisted cylinder with a radius of $295 \mathrm{~mm}$, which was installed with fasteners in the form of frames for fixing the samples $(35 \times 35 \mathrm{~mm}$ in dimension) (Fig. 1A). The linear speed of the rotor was $305-310 \mathrm{~cm} / \mathrm{s}$. Outside the rotor, one magnetron with a platinum target was situated (away from the plane of a cylinder of $45 \mathrm{~mm}$ ) and a second magnetron with an aluminum target at a distance of $95 \mathrm{~mm}$. Targets of magnetrons were spaced from each other by an angular distance $1 / 2 \pi$, and their centers were at the height of the suspended foil leaves. The diameters of the targets were $\varnothing=55 \mathrm{~mm}$. All layers were made under identical conditions of pressure, emptying the chamber to the base pressure and filling with argon to working pressure under dynamic vacuum and using the fixed operating parameters of the magnetrons (Table 1).

The Al layers obtained in the process under these conditions during 2 min had a thickness of 20 to $22 \mathrm{~nm}$ while the Pt layers had a thickness of 6 to $9 \mathrm{~nm}$. The system of magnetrons allowed independent sputtering of $\mathrm{Al}$ and $\mathrm{Pt}$ and formation of independent layers. During sputtering of $\mathrm{Al}$ and then $\mathrm{Pt}$, it was possible to obtain an $\mathrm{Al} / \mathrm{Pt}$ laminate, in which the $\mathrm{Al}$ nanolayer separated the steel bed from the Pt substrate. On the other hand, the simultaneous sputtering of $\mathrm{Al}$ and $\mathrm{Pt}$ led to the formation of the $\mathrm{Al}+\mathrm{Pt}$ composite nanolayer.

\subsection{Oxidation of the layers}

The oxidation of layers deposited on a steel substrate was carried out at $860^{\circ} \mathrm{C}$ in a stream of argon and oxygen mixture at atmospheric pressure (with $67.0 \%$ oxygen fraction). The total gas flow rate was maintained at $\mathrm{Q}\left(\mathrm{O}_{2}+\mathrm{Ar}\right)=53 \mathrm{~cm}^{3} / \mathrm{min}$. Testing equipment for oxidation was composed of an electric furnace with a vertically oriented quartz tube. The charge in the form of packets consisting of 8 bits separated from each other was placed in the central part of the furnace in the isothermal zone. Argon and oxygen were fed from below through the mixer filled with a cartridge mesh. The flow rate of each gas was controlled by Bronkhorst's flow regulators. It should be noted that the oxidation of film layers was preceded by oxidizing layer tests without additionally deposited layers at a temperature below $-840^{\circ} \mathrm{C}$ and with the fractions of oxygen varying from 20 to $70 \mathrm{wt} \%$ - to determine the effects of these factors on 
the rate of oxide weight gain (Fig. 1B-C). Fig. 1B shows the changes in weight gain of samples oxidized at temperatures of $840^{\circ} \mathrm{C}$ and $860^{\circ} \mathrm{C}$ in an atmosphere of $60 \% \mathrm{O}_{2} / \mathrm{Ar}$ and Fig. 1C depicts the changes in weight gain of samples oxidized at a temperatures of $860^{\circ} \mathrm{C}$ in atmospheres of $70 \% \mathrm{O}_{2} / \mathrm{Ar}, 60 \% \mathrm{O}_{2} / \mathrm{Ar}, 50 \% \mathrm{O}_{2} / \mathrm{Ar}$, and $40 \% \mathrm{O}_{2} / \mathrm{Ar}$

\subsection{The application of scanning electron and transmission microscopy for the examination of} surface morphology of oxide layers, metallic structures and oxide-metal composite layers

The morphology of the oxide layers was examined using the scanning electron microscope JSM $6500 \mathrm{LV}$ and transmission microscopy. The examinations were conducted at an accelerating voltage of $20 \mathrm{kV}$ under medium high vacuum. The success of the structural studies using transmission electron microscopy depends primarily on the quality of the specimen. The difficulty in its preparation increases as it relates to the connection area of two differing mechanical and electrical materials, such as steel with ceramic or glass, or brittle oxide layers on the metal. The preparation of thin foils of this type of samples is even now a big challenge. Specimens for testing were prepared by cutting the steel foil into small pieces (lobes) which were glued with each other in the form of packets. While preparing the crosssections, the thinning of the packets was carrying out through steps of mechanical grinding and lapping. Argon ion etching was carried out at a potential of $5 \mathrm{kV}$, at an angle of $14^{\circ} \mathrm{using}$ laser breakers.

Specimens in the form of thin films were also prepared by FIB technique using Quanta 3D device equipped with a manipulator Omniprobe. Prior to thinning, the samples were coated with a carbon layer of arc sprayed under vacuum to separate the Pt particles contained in the material of the platinum strip, which served as a mask during the cutting process using the ion beam and was vacuum deposited. In the case of $\mathrm{Al}_{2} \mathrm{O}_{3}$ whiskers, a carbon layer separating the mask Pt layer was deposited in order to improve contrast. The identification of the structures of Al and Pt layers deposited on steel and composite layers formed by the oxidation of steel with $\mathrm{Al}$ and Pt coatings was carried out using the transmission - scanning electron microscope (TEM / STEM) TECNAI FEG Super TWIN (200 kV), with the possibility of high resolution testing (HREM). The same technique was also used to evaluate the dispersion of the platinum in the composite layers

\section{Results and discussion}




\subsection{Kinetics of oxidation}

On the basis of the kinetics of steel oxidation (Fig. 1B-C), it was established that the time measuring the weight gain in the oxidation process, shall be 20 hours, for all variants of layers (Fig. 1D), excluding the start-up time of the furnace after loading the samples.

During starting-up the furnace to a temperature of $860^{\circ} \mathrm{C}$, the samples were placed in an argon atmosphere for 150 minutes. The temperature was stabilized in the reaction zone with an accuracy of $\Delta \pm 5^{\circ} \mathrm{C}$. After 20 hours of oxidation, the furnace was turned off, leaving the samples under argon to cool. Time to room temperature in the oxidizing zone was 120 min. A time of $20 \mathrm{~h}$ was found to be optimal for the temperature of $860^{\circ} \mathrm{C}$ and composition of $\mathrm{Ar} / 67 \% \mathrm{O}_{2}$ atmosphere. This was attributed to the beginning of the stabilization process, the weight gain of samples oxidized at a lower fraction of $\mathrm{O}_{2}(40$ and $50 \%)$ and relatively small increment in the oxide weight with an increased oxygen fraction (70\%) Fig. 1B-C.

\subsection{Morphology of oxide layers}

In the case of steel substrate (Fig. 2A-C) it was found that the growth of oxide layers is dominated by the formation of crystalline structures, which in the initial stage occasionally grow from the surface in the shape of one-dimensional forms - acicular (A). This is followed by their compaction and partial growth of some of these shapes to two-dimensional forms lamellar (B). As the process proceeds, the part of lamellar forms begins to take threedimensional shapes - irregular forms. Some of these crystallites forms a sub-layer of complex three-dimensional monoliths, and the remaining grow to form the single large whiskers, dagger-like shaped of anisotropic orientation (C). Due to the diversity of the oxide forms obtained in the process of oxidation, the central sites of samples free from defects were chosen. This was done to evaluate the impact of superimposed $\mathrm{Al}$ and $\mathrm{Pt}$ layers (and combinations thereof) on the morphology of oxide-metallic composite systems. Fig. 2 (D-E) depicts the SEM images; changes in the structure of oxide layers occurring on steel (s) with the duration of oxidation process: A - for 3h, B - after 12h, C - after $20 \mathrm{~h}$.

A feature that differs the scale obtained on the steel (s), Fig. 2A-C, from the scale of steel coated with a layer of $\mathrm{Al}(\mathrm{s}+\mathrm{Al})$. Fig. 2 (D-E), shows the presence of oxide in the form of long dagger-like whiskers. Fig. 3A, projecting above the solid forms pyramidal in shape (whiskers) and Fig. 3B depicts that the size of these whiskers is larger than the size of the whiskers present on uncoated steel.

Large dagger-like whiskers grown between solid forms are oriented, while the smaller ones form a kind of "compact mats". This represents a layer system in which the atoms of the 
layer with aluminum alloy atoms jointly take part in the formation of oxide structures. Consequently to this participation, aluminum atoms from the applied layer determine the larger whisker growth and contribute to the greater density of solid crystals at the surface of the steel.

With regard to the intense growth of aluminum oxide crystals resulting from the application of Al nanolayers, sputtering steel with Pt nanolayers has the different effect of inhibiting the growth of crystals for their compaction and homogenization. Probably the increase in density and homogenization of the oxide structures is an explanation of the comparable weight gain rates of oxides obtained on foils with $\mathrm{Al}$ and Pt layers (Fig. 1 D).

The morphology of the aluminum oxide obtained by oxidation of steel coated with Pt/Al laminate (Fig. 3a-b) where aluminum between steel and a Pt nanolayer, shows the presence of the oxide forms solid in shape (1) having a slightly smaller size and small daggerlike whiskers (2) characteristic of $\mathrm{Al}_{2} \mathrm{O}_{3}$ obtained on Al-coated steel and lamellar structures (3) characteristic of $\mathrm{Al}_{2} \mathrm{O}_{3}$ obtained on Pt-coated steel.

On the assessment of the oxide composite layers in terms of surface development obtained by oxidation of $\mathrm{Pt} / \mathrm{Al}$ laminate, it is clear that they are more developed than composite layers obtained by oxidation of Pt-coated steel, but less than oxide layers obtained on steel coated with Al-nanolayer. However, they are more homogeneous (Fig. 3a). In contrast, a large oxide weight gain can be explained as a result of additional $\mathrm{Pt}$ and $\mathrm{Al}$ synergism action in the process of oxide forming. A characteristic of these layers is the presence of large pyramid-shaped crystallites and dagger-like whiskers (Fig. 3b) rising from the substrate. This suggests that the deposited Pt nanolayer, which is a metal with a strong chemisorption of oxygen, promotes the faster formation of oxide crystals of deposited $\mathrm{Al}$ layers, than the crystals formed of Al contained in the substrate. In addition, Pt layer, depending on its thickness and continuity may constitute some difficulties for growing crystals, especially in the initial phase of their growth. Difficulty may results from interactions between fragments of platinum forming a layer and aluminum oxide nucleating agents. It results in affecting in this way the random direction in their rising and defecting. While the isotropic nature of the build-up of oxide crystallites promotes fragmentation of Pt layer and "absorption" of Pt nano-fragments into the deeper parts of the growing layer. The oxidation leads to the formation of scale built of randomly intermingled fine equiaxed crystals (nuggets) and whiskers.

The different characters have oxide layers obtained by oxidizing the composite layers of aluminum and platinum $(\mathrm{Pt}+\mathrm{Al})$ as shown in Fig. 3 c-d. The scale composed of chaotic 
intersecting small crystals (nuggets) and small whiskers have been obtained. In contrast to the layers obtained from oxidation of the laminate, this follows from the process of mixing the nanoparticles of aluminum and platinum while sputtering and depositing on the foil surface. In the process of oxidation of the metal composite $(\mathrm{Pt}+\mathrm{Al})$, platinum plays a double role: a metal with a strong chemisorption of oxygen, which promotes rapid oxidation of $\mathrm{Al}$ and a barrier that prevents the growth of oxide crystallites to large size.

Rapidly growing oxide crystals are accompanied by high stresses which cause deformation leading to the simultaneous formation of structures with different lumpy and elongated shapes that are strongly defected. Large stresses associated with crystal growth are also a reason for cracks and chaotic orientation in a large number of small whiskers and volumetric crystals. With increment in the oxide layer, the rate of oxygen transport to the lower-lying platinum particles is decreased that is followed by stabilization of the weight gain of the samples. This results in the formation of an aluminum oxide layer consisting of an outer portion made of loosely and randomly stacked oxide structures, but in a homogeneous way, and underneath it, is a layer of oriented crystallites increasing toward the surface which forced their mutual interaction. This represents a high porosity system comparable with the previous layers having a greater surface development.

\subsection{Electron-microscopic examinations of metallic and composite layer structure}

Examinations of a sectional view of the Al coating in the light field (STEM-BF) revealed that in the process of depositing the pure aluminum on steel, the coating continuous in character is formed which consist of three zones, where the central one reveals the characteristics of crystalline structure, Fig. 4a (1). This was confirmed by HRTEM examinations (Fig. 4b) revealing the zones of orderly arrangement of planes, and Moire's stripes formed by overlapping crystallites. Features indicative of the crystal structure do not exhibit the zone lying above and below the central zone.

Amorphous oxide layer forming a zone adjacent to the steel substrate (Fig.4a (2) may be explained by a lengthy process of foil oxidation in air at room temperature, prior to the process of depositing the Al layer. The nanolayer of amorphous oxide is formed naturally and its thickness does not exceed several nanometers $(d \leq 15 \mathrm{~nm})$. The observation of crosssectional layers of $\mathrm{Pt}$ deposited on a steel shows that primary oxide layers are separated by the alloy as in the case of aluminum layers. The sections of Pt layer and the primary oxide layer, presented in STEM image-BF (Fig. 4c) and by HREM image (Fig. 4d) shows that they form coherent good adhesion to the steel substrate. Since the Pt layer is continuous and the size of 
crystallites which constitute it is comparable with its thickness, one can assume that these grains results from coagulation of smaller polycrystals. First depositing the Al layer on steel substrate and next Pt can be considered as a solution to enrich FeCrAl steel with the $\mathrm{Al}$ component responsible for the formation of oxide crystals in the process of oxidation of so deposited nanolaminates. The interaction of crystals with Pt layer results in its division and fragmentation.

Our studies have shown (Fig.5a) that by deposition of metal (Al) the intrinsic oxide, layer (1) is formed and a second oxide nano-film (2) which is formed in the initial stage of the process is probably due to the reaction of aluminum with oxygen molecules adsorbed by the layer of intrinsic oxide. If it is possible to extract the regions in the Al layer (which indicate the crystalline structure) then in the oxide layer formed on the primary layer, there were no obvious areas of crystallization. If there are crystallites which cannot be ruled out, they are so small that they do not give diffraction reflexes. The study has also shown (Fig. 5b) that on deposition of platinum on the aluminum layer, there was formation of layers which in some sites represents strings of the spherical polycrystalline grains (1) at some sites continuous and of uniform thickness.

In the areas where there were no enumerated defects of the aluminum layer in the form of clusters insular in nature, there was also not enumerated insular nature of the platinum layer. However, there are several noteworthy cracks that occur between the intrinsic oxide layer and the oxide layer formed during the aluminum deposition process (2). The reason may be the stresses which arise during the formation of platinum layer. This is due to the fact that the microcracks do not occur when only aluminum layers are deposited.

The simultaneous sputtering of $\mathrm{Pt}$ and $\mathrm{Al}$ from separate sources made it possible to obtain composite nanolayers by mutual mixing of the components. There is formation of layers integrated with the steel substrate that are continuous in nature and are loosely arranged spherically shaped large grains (Fig. 5c). These grains are made of Pt crystallites (1) forming the spherical coat systems (dark areas) covering the polycrystalline Al grains, marked by lighter areas (2). The system is shown in the diagram (d). In layers that are continuous in character, one can easily distinguish two zones. The upper zone is having a crystalline structure similar to that of spheroidal grains (3) and a lower one formed of small $\mathrm{Pt}$ polycrystalline aggregates loosely connected via Al (4). The lower zone forms a solid piece with the intrinsic oxide layer (5).

\subsection{Electron-microscopic examinations of oxide layer structure and Pt dispersion}


In the cross-sections of composite oxide layers obtained by oxidation of nanolayers $\mathrm{Al}$ and $\mathrm{FeCrAl}$ steel, there were identified precipitates of solid and cubic forms which were mainly placed at the metal substrate and growing pint of these whiskers Fig. 6 a. Electron diffraction examinations[29] has shown that $\alpha-\mathrm{Al}_{2} \mathrm{O}_{3}$ phase (1) is situated in these places. Adjacent to whiskers of $\alpha-\mathrm{Al}_{2} \mathrm{O}_{3}$ phase, there are whiskers of $\theta-\mathrm{Al}_{2} \mathrm{O}_{3}$ phase (2) that arise from substrate. There was no proof of existence of the original oxide layer formed on foil in a natural way. Phase $\alpha-\mathrm{Al}_{2} \mathrm{O}_{3}$, Fig.6b (1), also occurs in the form of a large compact solid forms between whiskers $(2,3)$, and in the form of aggregation of smaller crystalline forms. Their appearance and lateral growth reduces the whiskers rise freely, which causes their deformation. This is probably due to the impact of compressive forces originating from expansion. As a result the regions with high saturation of solid crystallites whiskers have a much smaller area of direct contact with the steel substrate and perturbed growth direction.

Morphological tests on the oxide layers by SEM revealed that the presence of $\mathrm{Pt}$ nanolayer on steel in the process of oxidation slows the growth of crystals of the oxide into the atmosphere. The sections (Fig. 6c) shows that it results in the formation of compact polycrystalline structures of a mixed phase forming the conical large bases. There is a lack of the initial oxide layer in a zone near the foil surface and one may observe spherical forms of $\alpha-\mathrm{Al}_{2} \mathrm{O}_{3}$ phase (1). Their size is smaller compared to those formed using $\mathrm{Al}$ nanolayers and close to the crystalline forms obtained on the uncoated foil. TEM studies showed that conical forms results in the formation of crystals that are mounted on the base to steel substrate, whereas the crystallites of $\alpha-\mathrm{Al}_{2} \mathrm{O}_{3}$ phase (formed by extrusion mechanism) are elongated in the shape of whiskers (2). Due to their longer dimension, the $\alpha-\mathrm{Al}_{2} \mathrm{O}_{3}$ whiskers extend above the zone of direct contact with substrate to form a system of separated crystals covered partly by platinum nanolayer. A small amount of platinum in the form of dispersed particles remains within the oxide layer due to "bricking" effect by oxide crystals which has a higher growth rate in the initial stage of oxidation.

The presence of Pt particles on the surface of oxide crystallites indicates a process of mechanical grinding of Pt nanolayer which may likely take place at an early stage of growing up crystals on the foil surface and then their further growth. A small amount of Pt at half height or near the tops of the crystallites indicates that only part of the platinum is supported on the whisker surfaces. Most of ultrafine particles of platinum in the dispersion state forms a sub-zone at the foil surface. In the absence of intrinsic oxide layer, it can be assumed that it was dispersed and transformed during the crystal growth. Both the sizes and shapes of Pt particles similar to spherical show coalescence, which occurs in case of rupture of a nanolayer 
by growing oxide crystallites and long term exposure to temperatures in the process of oxidation. Coagulation process was also favored by the construction of $\mathrm{Pt}$ layer deposited on steel (containing the oval polycrystalline grains). Coating the intrinsic oxide layer on FeCrAl steel, first with Al metallic layer and then with Pt causes the decline in the intrinsic oxide in the process of oxidation. Probably, this layer was diffused as a result of growth of aluminum oxide crystals from the steel substrate and crystals of embedded aluminum. The porous structure of the intrinsic oxide is conductive to diffusion under the aluminum layer which may allow the simultaneous growth of oxide grains in the direction of the steel substrate and the oxidizing atmosphere.

Consequently a very consistent nanolayer zone adjacent to the foil (Fig. 7a) was obtained that is composed of solid crystallites (1) identified previously as $\alpha-\mathrm{Al}_{2} \mathrm{O}_{3}$ phase. The layer of platinum located on the surface of aluminum layer assisted in the Al oxidation, thus contributing to the rapid growth of crystallites and oxide whiskers with highly defected structure which divide Pt layer into smaller pieces. Some of them are trapped between oxide crystals and some coalesces to form large particles which may produce above the oxide crystals (2). This process is schematically shown in Fig.7b.

In the case of $\mathrm{Pt}+\mathrm{Al}$ composite, the larger share of $\mathrm{Al}$ in the surface zone of metal foil (Fig. 5c) and the loose arrangement of Pt polycrystals in spheroidal grains with a smaller share of $\mathrm{Al}$ and separation of $\mathrm{Pt}$ grains with $\mathrm{Al}$ grains is the reason for the diversity of $\mathrm{Pt}$ particle density in the resulting oxide layers and its fragmentation (Fig. 8 a). The largest concentration of ultrafine Pt crystals is present in zone (1) corresponding to the composite, emerging in zones 2 and 3 (Fig. 5c) with decrease in the direction of steel Pt fraction relative to Al. The oxide system based on the composite nanolayer in comparison to the oxide system based on Pt nanolayer and Pt/Al laminate is marked by occurrence of finer Pt particles, a greater range of occurrence in the oxide layer and greater uniformity of size. Ultrafine Pt particles are formed as a result of good mixing of platinum with aluminum which prevents the process of coagulation during the aluminum oxidation. In contrast, larger particles (2) are the remains of platinum which is part of spheroidal grains in which the share of $\mathrm{Al}$ is smaller that promotes the process of $\mathrm{Pt}$ coagulation. The occurrence of Pt particles inside the grains (3) can be explained by a high sorption activity of $\mathrm{Pt}$ in relation to oxygen and due to the neighborhood of $\mathrm{Al}$ atoms around $\mathrm{Pt}$ particles. This promotes encapsulation of Pt particles by oxide particles in the first oxidation phase and then encased in whisker structure within the duration of the oxidation process. The observations also show that in some cases, the growing oxide crystals capture fragments of the broken Pt nanolayer and in the form of particles they 
raise them on their surfaces (4). The significant feature however is Pt particle dispersion by extending the entrained spheroidal grain fragments on the surface of the growing whiskers (Fig. 8a-b).

This can be seen on the example of streaks on the slopes of whiskers (next to the dashed lines), or in the form of a uniform distribution on the surfaces of whiskers exposed from the front. A larger fraction of $\mathrm{Al}$ in the primary oxide zone is the cause of significantly smaller Pt fraction in this zone after the oxidation process. The process of Pt dispersion caused by oxidation of high temperature $\mathrm{Pt}+\mathrm{Al}$ composite is shown schematically in Fig. 8ce. In the first stage of the process, there is adsorption and diffusion of oxygen into the grain. In the second phase, there is the growth of $\mathrm{Al}_{2} \mathrm{O}_{3}$ grains due to $\mathrm{Al}$ oxidation inside the spherical grains and the continuous $\mathrm{Pt}+\mathrm{Al}$ layer as well as under this layer. The oxide crystallites being formed tear all Pt coatings on the nanoparticles. The coating of spherical grains may be torn in all directions. The disruption of continuous coatings is supported by the growth of oxide crystals of aluminum contained in the alloy.

The third phase of the process includes crystal growth and transportation of torn oxide particles of platinum coating to the upper parts of the oxide layer. Growth of oxide crystals from grains and growth of oxide crystals from Al contained in the alloy leads to partial occlusion of Pt particles with aluminum oxide which is not preferred. However, for a highly efficient dispersion of the platinum coatings to the nanoparticles, it provides a marginal problem.

\section{Conclusions}

Based on the above research, it can be concluded that the presented method of generating catalytic layers fully meets the core requirements to a greater extent in comparison to the waschcoat method, and is also simpler and material-saving. Following are the key points of the research work carried out:

1. Tests on FeCrAl steel oxidation kinetics have shown that there is an optimal fraction of oxygen in the $\mathrm{Ar} / \mathrm{O}_{2}$ atmosphere, which should not exceed $70 \%$ volume and where the greatest oxide weight gains for certain temperature-time conditions were found.

2. Tests on steel additionally coated with $\mathrm{Al}, \mathrm{Pt}$ nanolayers, $\mathrm{Pt} / \mathrm{Al}$ laminate and nanolayers of $\mathrm{Pt}+\mathrm{Al}$ composite have revealed that the direct presence of $\mathrm{Pt}$ nanolayers on steel 
promotes the growth of the oxide layer so that it is comparable with the growth obtained for the Al layer. The catalytic effect of Pt on the oxide weight gain occurred clearly in the case of oxidation of the Pt/Al laminate layer, and to a lesser extent in the case of oxidation of the $\mathrm{Pt}+\mathrm{Al}$ composite layer. This is due to the synergistic action of $\mathrm{Pt}$ and $\mathrm{Al}$ in the process of oxidation.

3. Oxidation of an additional Al layer on steel leads to the formation of a hybrid Al oxide originating from the steel substrate and the layer. A characteristic feature of scale is the occurrence of long dagger-like whiskers between solid forms and smaller whiskers that constitutes the compact layer system. The growth of elongated whiskers has been determined by embedded Al-nanolayer.

4. Compared to the case of Al layer, the steel surface modification by deposition of $\mathrm{Pt}$ nanolayer results in the inhibition of growth and density of crystal structures of oxide, which arises from aluminum contained in steel. As a result, the layer created is more homogeneous and has higher porosity. A characteristic feature of this layer is the occurrence of the conical form of oxides, wide at the base and separated from each other. They are fragmentary covered, as far homogeneous as to size, with Pt particles originating from the division of nanolayers.

5. Another modification which consists in deposition of Pt/Al laminate on steel leads to (in comparison to the previous layer) a better surface development. However, due to the synergistic action of $\mathrm{Pt} / \mathrm{Al}$ with respect to oxygen, there is a rapid oxide crystal growth and closing the larger areas with Pt particles which coalesce leading to the formation of large particles.

6. In the process of depositing layers from $\mathrm{Pt}+\mathrm{Al}$ composite, there occurs intermixing of two components and partial occlusion of Pt particles with Al particles. Already at this stage, there arise systems conductive to the dispersion of $\mathrm{Pt}$ in the process of oxidation. In the oxidation process, platinum promotes rapid oxidation of $\mathrm{Al}$ (thanks to strong chemisorption of oxygen,) but on the other hand provides a barrier to the growth of oxide crystallites to large size.

7. Fast-growing crystals were accompanied by high stresses that cause defects and deformities leading to the simultaneous formation of crystals of various solid and elongated shapes. Large stresses associated with crystal growth are also reason for cracks and chaotic orientation of large number of small whiskers. This leads to the formation of layers built of the loosely stacked oxide crystals of unbalanced isometrics and the underneath layer with preserved directivity of crystallite growth. This results in 
an arrangement that provides in comparison to the previous layers the best access of external factors to the best dispersed Pt particles.

8. The presented technology allows the introduction of a catalytically active element $-\mathrm{Pt}$ at the stage of oxide crystal growth which become its matrix and carrier. It is a simple, economical and waste-free. It provides good integration of the layer with the substrate resulting from the growth of oxide crystallites of steel in the high temperature oxidation process.

\section{References:}

[1] Y.K. Mishra, S. Kaps, A. Schuchardt, I. Paulowicz, X. Jin, D. Gedamu, S. Freitag, M. Claus, S. Wille, A. Kovalev, S.N. Gorb, R. Adelung, Ceramics: Fabrication of Macroscopically Flexible and Highly Porous 3D Semiconductor Networks from Interpenetrating Nanostructures by a Simple Flame Transport Approach (Part. Part. Syst. Charact. 9/2013), Part. Part. Syst. Charact. 30 (2013) 731-731. doi:10.1002/ppsc.201370034.

[2] Y.K. Mishra, R. Adelung, $\mathrm{ZnO}$ tetrapod materials for functional applications, Mater. Today. 21 (2018) 631-651. doi:10.1016/j.mattod.2017.11.003.

[3] A. Muhulet, F. Miculescu, S.I. Voicu, F. Schütt, V.K. Thakur, Y.K. Mishra, Fundamentals and scopes of doped carbon nanotubes towards energy and biosensing applications, Mater. Today Energy. 9 (2018) 154-186. doi:10.1016/j.mtener.2018.05.002.

[4] G. Madhumitha, J. Fowsiya, S.M. Roopan, V.K. Thakur, Recent advances in starch-clay nanocomposites, Int. J. Polym. Anal. Charact. 23 (2018) 331-345. doi:10.1080/1023666X.2018.1447260.

[5] J. Wróblewska-Krepsztul, T. Rydzkowski, G. Borowski, M. Szczypiński, T. Klepka, V.K. Thakur, Recent progress in biodegradable polymers and nanocomposite-based 
packaging materials for sustainable environment, Int. J. Polym. Anal. Charact. 23 (2018) 383-395. doi:10.1080/1023666X.2018.1455382.

[6] J.C. Ding, T.F. Zhang, R.S. Mane, K.-H. Kim, M.C. Kang, C.W. Zou, Q.M. Wang, Lowtemperature deposition of nanocrystalline $\mathrm{A} 12 \mathrm{O} 3$ films by ion source-assisted magnetron sputtering, Vacuum. 149 (2018) 284-290. doi:10.1016/j.vacuum.2018.01.009.

[7] S.R. Anjum, V.N. Narwade, K.A. Bogle, R.S. Khairnar, Graphite doped Hydroxyapatite nanoceramic: Selective alcohol sensor, Nano-Struct. Nano-Objects. 14 (2018) 98-105. doi:10.1016/j.nanoso.2018.01.010.

[8] A. Deepi, G. Srikesh, A.S. Nesaraj, Electrochemical performance of Bi2O3 decorated graphene nano composites for supercapacitor applications, Nano-Struct. Nano-Objects. 15 (2018) 10-16. doi:10.1016/j.nanoso.2018.03.003.

[9] S. Suriyakumar, N. Angulakshmi, A.M. Stephan, Better performing composite cathode encompassing graphene and magnesium aluminate for $\mathrm{Li}-\mathrm{S}$ batteries, Nano-Struct. Nano-Objects. 11 (2017) 46-55. doi:10.1016/j.nanoso.2017.06.001.

[10] M. Ghanbari, M. Salavati-Niasari, T14CdI6 Nanostructures: Facile Sonochemical Synthesis and Photocatalytic Activity for Removal of Organic Dyes, Inorg. Chem. 57 (2018) 11443-11455. doi:10.1021/acs.inorgchem.8b01293.

[11] O. Lupan, N. Wolff, V. Postica, T. Braniste, I. Paulowicz, V. Hrkac, Y.K. Mishra, I. Tiginyanu, L. Kienle, R. Adelung, Properties of a single SnO2:Zn2SnO4 Functionalized nanowire based nanosensor, Ceram. Int. 44 (2018) 4859-4867. doi:10.1016/j.ceramint.2017.12.075.

[12] J. Gröttrup, F. Schütt, D. Smazna, O. Lupan, R. Adelung, Y.K. Mishra, Porous ceramics based on hybrid inorganic tetrapodal networks for efficient photocatalysis and water purification, Ceram. Int. 43 (2017) 14915-14922. doi:10.1016/j.ceramint.2017.08.008. 
[13] J. Gröttrup, I. Paulowicz, A. Schuchardt, V. Kaidas, S. Kaps, O. Lupan, R. Adelung, Y.K. Mishra, Three-dimensional flexible ceramics based on interconnected network of highly porous pure and metal alloyed ZnO tetrapods, Ceram. Int. 42 (2016) 8664-8676. doi:10.1016/j.ceramint.2016.02.099.

[14] F. Davar, M. Salavati-Niasari, Synthesis and characterization of spinel-type zinc aluminate nanoparticles by a modified sol-gel method using new precursor, J. Alloys Compd. 509 (2011) 2487-2492. doi:10.1016/j.jallcom.2010.11.058.

[15] V.K. Thakur, Y. Li, H. Wu, M.R. Kessler, Synthesis, characterization, and functionalization of zirconium tungstate $(\mathrm{ZrW} 2 \mathrm{O} 8)$ nano-rods for advanced polymer nanocomposites, Polym. Adv. Technol. 28 (2017) 1375-1381. doi:10.1002/pat.4014.

[16] M.-F. Lin, V.K. Thakur, E.J. Tan, P.S. Lee, Dopant induced hollow BaTiO3 nanostructures for application in high performance capacitors, J. Mater. Chem. 21 (2011) 16500-16504. doi:10.1039/c1jm12429c.

[17] M. Salavati-Niasari, T. Khosousi, S. Hydarzadeh, Highly selective esterification of tertbutanol by acetic acid anhydride over alumina-supported $\mathrm{InCl} 3, \mathrm{GaCl} 3, \mathrm{FeCl} 3, \mathrm{ZnCl}$, $\mathrm{CuCl} 2, \mathrm{NiCl} 2, \mathrm{CoCl} 2$ and $\mathrm{MnCl} 2$ catalysts, J. Mol. Catal. Chem. 235 (2005) 150-153. doi:10.1016/j.molcata.2005.03.042.

[18] M. Adamowska, P. Da Costa, Structured Pd/ $\gamma$-A12O3 Prepared by Washcoated Deposition on a Ceramic Honeycomb for Compressed Natural Gas Applications, J. Nanoparticles. (2015). doi:10.1155/2015/601941.

[19] T. Zhou, L. Li, J. Cheng, Z. Hao, Preparation of binary washcoat deposited on cordierite substrate for catalytic applications, Ceram. Int. 36 (2010) 529-534. doi:10.1016/j.ceramint.2009.09.027.

[20] J. Hwang, H.-J. Ha, J. Ryu, J.-J. Choi, C.-W. Ahn, J.-W. Kim, B.-D. Hahn, W.-H. Yoon, H. Lee, J.-H. Choi, Enhancement of washcoat adhesion for SCR catalysts to convert 
nitrogen oxide using powder spray coating of $\mathrm{TiO} 2$ on metallic honeycomb substrate, Catal. Commun. 94 (2017) 1-4. doi:10.1016/j.catcom.2017.02.002.

[21] D. Wu, Y. Zhang, Y. Li, Mechanical stability of monolithic catalysts: Improving washcoat adhesion by FeCrAl alloy substrate treatment, J. Ind. Eng. Chem. 56 (2017) 175-184. doi:10.1016/j.jiec.2017.07.010.

[22] A.M. Leman, J. Afiqah, F. Rahman, D. Feriyanto, S. Zakaria, R. Rahmad, Catalytic Converter Developed By Washcoat Of $\gamma$-Alumina On Nickel Oxide (Nio) Catalyst In FeCrAl Substrate For Exhaust Emission Control : A Review, MATEC Web Conf. 78 (2016) 01045. doi:10.1051/matecconf/20167801045.

[23] R. Balzarotti, M. Ciurlia, C. Cristiani, F. Paparella, R. Balzarotti, M. Ciurlia, C. Cristiani, F. Paparella, Washcoat Deposition of Ni- and Co-ZrO2 Low Surface Area Powders onto Ceramic Open-Cell Foams: Influence of Slurry Formulation and Rheology, Catalysts. 5 (2015) 2271-2286. doi:10.3390/catal5042271.

[24] D. Zhang, L. Zhang, B. Liang, Y. Li, Effect of Acid Treatment on the High-Temperature Surface Oxidation Behavior of FeCrAlloy Foil Used for Methane Combustion Catalyst Support, Ind. Eng. Chem. Res. 48 (2009) 5117-5122. doi:10.1021/ie8019664.

[25] K. Reszka, J. Rakoczy, Z. Zurek, A. Czyniewski, A. Gijewicz, M. Homa, Catalytic properties of Al2O3 deposited by ion sputtering using DC and, Vacuum. 78 (2005) 149155. doi:10.1016/j.vacuum.2005.01.018.

[26] M. Staszuk, D. Pakula, G. Chladek, M. Pawlyta, M. Pancielejko, P. Czaja, Investigation of the structure and properties of PVD coatings and ALD plus PVD hybrid coatings deposited on sialon tool ceramics, Vacuum. 154 (2018) 272-284. doi:10.1016/j.vacuum.2018.04.032. 
[27] W.M. Seidl, M. Bartosik, S. Kolozsvari, H. Bolvardi, P.H. Mayrhofer, Influence of Ta on the fracture toughness of arc evaporated Ti-Al-N, Vacuum. 150 (2018) 24-28. doi:10.1016/j.vacuum.2018.01.028.

[28] B. Wu, Y. Yu, J. Wu, I. Shchelkanov, D.N. Ruzic, N. Huang, Y.X. Leng, Tailoring of titanium thin film properties in high power pulsed magnetron sputtering, Vacuum. 150 (2018) 144-154. doi:10.1016/j.vacuum.2018.01.039.

[29] K. Reszka, J. Morgiel, J. Reszka, Structure and properties of an alumina/amorphousalumina/platinum catalytic system deposited on FeCrAl steel, J. Microsc. 224 (2006) 46-48. doi:10.1111/j.1365-2818.2006.01657.x. 


\section{Figure Captions:}

Fig. 1 (A). The scheme of deposition stand for $\mathrm{Al}$ and Pt nanolayers.

Fig. 1 (B). Changes in weight gain of samples oxidized at: a - temperatures of $840^{\circ} \mathrm{C}$ and $860^{\circ} \mathrm{C}$ in an atmosphere of $60 \% \mathrm{O}_{2} / \mathrm{Ar}$;

Fig. 1 (C). Temperature of $860^{\circ} \mathrm{C}$ in atmospheres of $70 \% \mathrm{O}_{2} / \mathrm{Ar}, 60 \% \mathrm{O}_{2} / \mathrm{Ar}, 50 \% \mathrm{O}_{2} / \mathrm{Ar}, 40 \%$ $\mathrm{O}_{2} / \mathrm{Ar}$

Fig. 1(D). The weight gains of samples oxidized at a temperature of $860^{\circ} \mathrm{C}$ in an atmosphere of $\mathrm{Ar} / 67 \% \mathrm{O}_{2} ; 1$ - steel, 2 - steel + Al layer, 3 - steel + Pt layer, 4 - steel + laminate Pt/Al, 5 steel + composite layer $(\mathrm{Pt}+\mathrm{Al})$

Fig. 2 (A-C). SEM images; changes in the structure of oxide layers occurring on steel (s) with the duration of oxidation process: $\mathrm{a}$ - for $3 \mathrm{~h}, \mathrm{~b}$ - after $12 \mathrm{~h}, \mathrm{c}-$ after $20 \mathrm{~h}$.

Fig. 2 (D-E). SEM images; formation of a composite aluminum oxide layer obtained with the participation of aluminum atoms from steel and the deposited $\mathrm{Al}$ layer $(\mathrm{s}+\mathrm{Al})$.

Fig. 3 (A-B). SEM images; configuration of the composite layer surfaces obtained by oxidation of steel laminate coated with Pt/Al laminate: (A) - homogeneous structure of oxide crystals, (B) - image of dagger-like whiskers.

Fig. 3. (C-D) SEM images, the configuration of surface layers of the composite obtained by the oxidation of steel coated with a $\mathrm{Pt}+\mathrm{Al}$ composite: (C) - small crystals randomly arranged in the form of irregular solids and fine whiskers, (D) - different size oxide crystals forming the spatially porous (spongy) structure.

Fig. 4 (a-b). Cross-sectional view of Al nanolayer deposited on steel; (a) - image STEM-BF, (1) - the crystalline structure, (2) - oxide layer amorphous in character formed on the surface of the steel in an intrinsic manner, c - carbon layer deposited under vacuum for processing, (b) - HREM image from site (1), there are visible planes of atoms and Moire's effect, caused by overlapping the crystals

Fig. 4 (c-d). Cross-sectional view of Pt nanolayer deposited on steel; (c) - image STEM-BF (1) - Pt nanolayer, (2) - amorphous oxide layer formed on the surface of steel in intrinsic manner, c - carbon layer deposited under vacuum for testing, (d) - HREM image from site (1), there are shown planes of atom arrangements and Moire's effect, caused by the crystals overlapping 
Fig. 5 (a-b). Cross sectional view of laminate in the form of $\mathrm{Pt} / \mathrm{Al}$ nanolayer deposited on steel; (a) - STEM-BF image, (1) - oxide layer formed on the steel surface in an intrinsic manner amorphous in character (2) - aluminum oxide nanolayer formed during the first stage of Al deposition, $\mathrm{c}$ - carbon layer deposited under vacuum for processing, (b) - STEM-BF image, cross-section through Pt layer insular in character (1), with visible cracks between two oxide layers (2)

Fig. 5 (c-d). c- STEM-BF image, a fragment of the $\mathrm{Pt}+\mathrm{Al}$ composite layer with separate polycrystalline grains; (1) spherically arranged Pt grains, (2) polycrystalline Al grain, (3) Pt continuous layer, (4) sub-layer made of Pt and Al, (5) intrinsic oxide layer, (d) - schematic grain built of $\mathrm{Pt}$ and $\mathrm{Al}$ polycrystalline

Fig. 6 (a-b). BF-TEM image, fragments of oxide layer obtained by oxidation of the steel coated with $\mathrm{Al}$ nanolayer; Fig.6a (1) solid crystals of $\alpha-\mathrm{Al}_{2} \mathrm{O} 3$ phase with whiskers growing out on them, (2) whiskers of $\theta-\mathrm{Al}_{2} \mathrm{O} 3$, Fig.6b (1) compact solid polycrystals of $\alpha-\mathrm{Al}_{2} \mathrm{O}_{3}$ phase, (2.3) whiskers of $\theta-\mathrm{Al}_{2} \mathrm{O} 3$ phase drawn aside by solid crystal.

Fig. 6c. BF-TEM image, partial cross-section of the composite layer, oxide polycrystal with dispersive located Pt particles; 1- spherical form of $\alpha-\mathrm{Al}_{2} \mathrm{O}_{3}$ phase, 2- whisker of $\alpha-\mathrm{Al}_{2} \mathrm{O}_{3}$ phase

Fig. 7 (a). BF-TEM image, a partial cross-section of composite layer obtained by oxidation of $\mathrm{Pt} / \mathrm{Al}$ laminate deposited on steel; 1- solid polycrystals of $\alpha-\mathrm{Al}_{2} \mathrm{O}^{3}$ phase, 2- Pt particles after coalescence

Fig. 7 (b). Schematic division of Pt nanolayer due to oxide crystal growth and coalescence of Pt particles; (left) - laminate before oxidation, (right) - composite after oxidation; 1- intrinsic oxide layer, 2- FeCrAl steel

Fig. 8 (a-b). BF-TEM image, (a) section through the oxide layer resulting from the oxidation of $\mathrm{Pt}+\mathrm{Al}$ composite: 1 - zone of greatest density of the smallest Pt particles, 2 - Pt grain after coalescence, 3 - Pt grains built into oxide crystals, 4 - zone of oxide crystal with Pt particles on its surface; (b) - Pt particles arranged on the surface of crystals in the form of streaks, and the dissolution of the Pt layer of spherical grains (along the broken line)

Fig. 8 (c-e). Process flow diagram of platinum dispersion through the growth of oxide crystals from composite coating containing Pt + Al grains; (a) - adsorption of oxygen, (b) - oxide crystal growth and beginning of Pt nanolayer tearing, (c) - Pt dispersion on the surface of growing oxide crystals 
Table Captions:

Table 1. Operating parameters of $\mathrm{DC}$ magnetrons during the deposition of $\mathrm{Al}$ and $\mathrm{Pt}$ nanolayers 


\section{On the morphological investigation of $\mathrm{Pt}$ dispersion and structure of alumina-platinum composites obtained by thermal oxidation of Al-Pt nano thin layers}

Reszka, Kazimierz

Elsevier

Reszka K, Morgiel J, Rydzkowski T, Thakur VK. (2019) On the morphological investigation of Pt dispersion and structure of alumina-platinum composites obtained by thermal oxidation of Al-Pt nano thin layers. Nano-Structures and Nano-Objects, Volume 17, February 2019, pp. 229-238 https://doi.org/10.1016/j.nanoso.2019.01.007 Downloaded from Cranfield Library Services E-Repository 